\title{
Research on Expert System for Hydraulic Support in Fully Mechanized Mining Based on FTA Xiu-cai GUO ${ }^{1, a}$, Ren-jun WANG ${ }^{1, b}$ \\ ${ }^{1}$ Xi'an University of Science and Technology, Xi'an, 710054, China aguoxiucai@163.com, b664740245@qq.com
}

Keywords: Coal Mine, Hydraulic Support, Fault Tree, Fault Diagnosis, Expert System.

\begin{abstract}
According to the problem that the fault of the hydraulic support was difficult and the recognition rate was low, the fault diagnosis method was put forward based on the FTA fully mechanized coal mining hydraulic support. This method was integrated with fault tree diagnosis technology and expert system. The failure types and causes of the hydraulic support are researched in detail, and the fault tree model is created with the column as an example. The visual interface of the system is friendly based on VisTwo software platform, so that the system is simple, accurate and accurate. It is of great significance to the safety production of coal mine.
\end{abstract}

\section{Introduction}

Because the fully mechanized coal mining hydraulic support is composed of complex and the hydraulic system fault is changeable and hidden, the condition monitoring is difficult [1]. The expert system based on fault tree is established in the paper using VisTwo software platform of Marco. Meanwhile, the vibration and noise signals are used as the characteristic parameters for diagnosis. Through knowledge acquisition, reasoning technology, knowledge representation and dynamic database technology, failure diagnosis and treatment of hydraulic system is more simple and accurate. To a certain extent, the system ensures the safety of coal mine production.

\section{Design of Fault Diagnosis Expert System of Hydraulic Support}

\section{Composition of Expert System for Fault Diagnosis}

The fault diagnosis expert system of fully mechanized mining hydraulic can solve the problem of the actual problem based on symbolic reasoning. The system is mainly based on knowledge and reasoning to get the judgment and decision. Support mainly includes human machine interface, dynamic database, inference engine and knowledge base[2], Its system structure is shown in Figure1. 


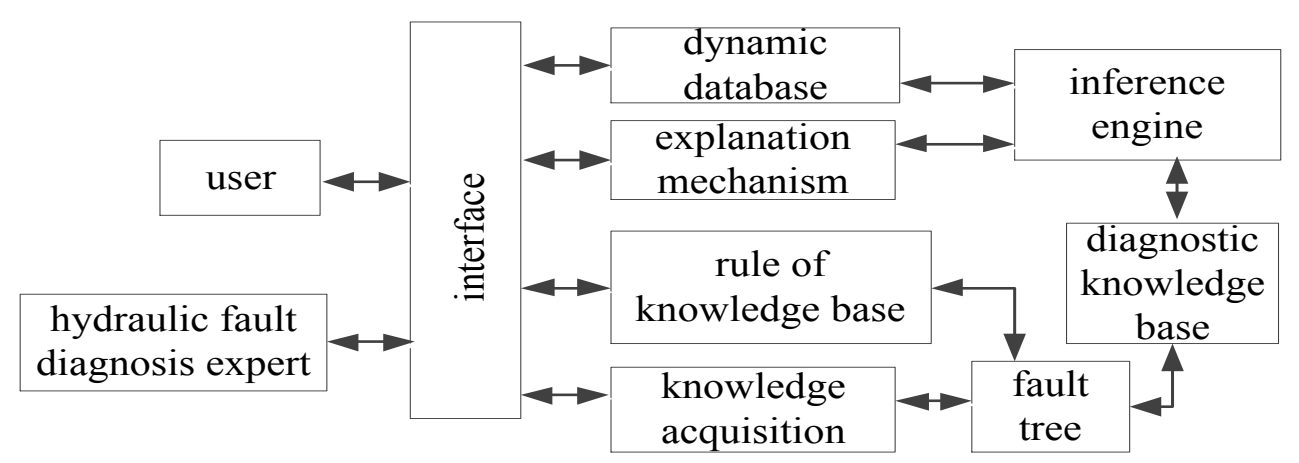

Figure 1. Fault diagnosis expert system for hydraulic support

Diagnostic knowledge base is used to store all kinds of fault phenomena, diagnosis rules and detection tips; the dynamic database stores all kinds of information in the process of reasoning, such as the description of the problem, the information of the system parameters, the conclusion and suggestion of the diagnosis and so on; inference engine for fault diagnosis and analysis drawsthe conclusion of diagnosis; Interface realize the information exchange with the system.

\section{Characteristic Parameter}

Fully mechanized mining hydraulic support system mainly includes support column, support jack, hydraulic valve and support components, through the hydraulic operating valve and pump fluid to achieve the lifting and passage of the hydraulic support and so on. The parameters of the hydraulic system are varied, such as vibration noise, pressure, flow rate and so on. The failure of hydraulic system is mainly caused by the seal. When the pump leakage is produced, the pressure difference between the inside and outside of the hydraulic cavity is changed, then the signal of vibration and noise is generated at the leak point. The vibration noise signal is used as the characteristic parameter to provide accurate information for the diagnosis system by piezoelectric acceleration sensor with high sensitivity.

\section{Establishment of Expert System Knowledge Base}

The expert system fault tree model is established by analyzing the reason of failure, which provides an important basis for the diagnosis rules of expert system.So, the difficulty of obtaining system knowledge is reduced, and the efficiency of system knowledge acquisition is improved.

\section{Analysis of Fault Tree}

The top event of the system fault tree is determined by the simple logic tree model. Through the potential causes, the fault is found and the logical relationship with their specific symbolic logic (logic and gate, or gate) express. The fault event is decomposed by reason, and then the fault tree model of the system is generated including the fault tree in the middle of the event and the end of the event. The ZZ4000/17/35 type support shield support is taken as an example in paper. Its hydraulic working principle is shown in Figure 2. 


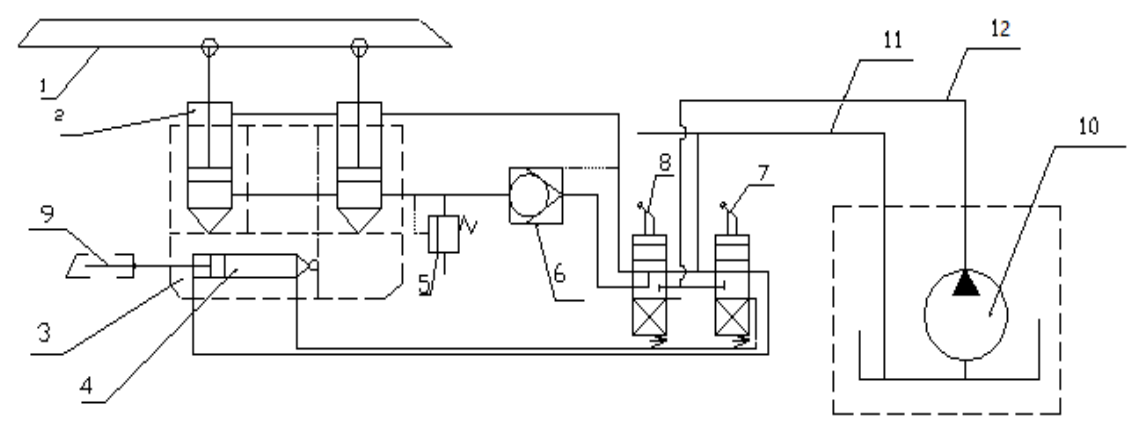

1 top-beam 2 column 3 bedplates 4 push jack 5 safe-valve 6 Pilot-operated Check 7/8 operating valve 9 transport pan 10 emulsion pump station 11 Main liquid supply pipe 12 Main return liquid pipe

Figure 2. The working principle of ZZ4000/17/35

The hydraulic system shown in Figure 2 is composed of Jack, control valve, control valve group, two-way valve and pipeline, etc.Hydraulic support complete the support, cutting, moving frame and conveyor and other operations with the mutual coordination of Control valve and high pressure liquid of pumping station. The failure of ZZ4000/17/35 type hydraulic support system is selected as the top event. The causes include 5 faults, which is connected to each other by "or" doors, column failure, Jack failure, operating valve fault pipeline fault, safety valve failure. The fault tree is shown in Figure 3.

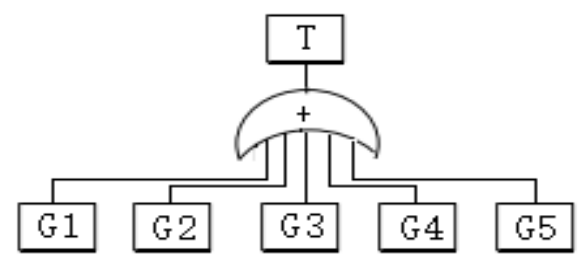

Figure 3. The fault tree of hydraulic support

\section{Establishment of Fault Tree of Expert System}

The establishment of system fault tree is the foundation and key link of fault tree analysis [5]. The failure of the hydraulic support column is taken for an example to establish the fault tree as shown in Figure 4. The corresponding event list is shown in Table 1[3].

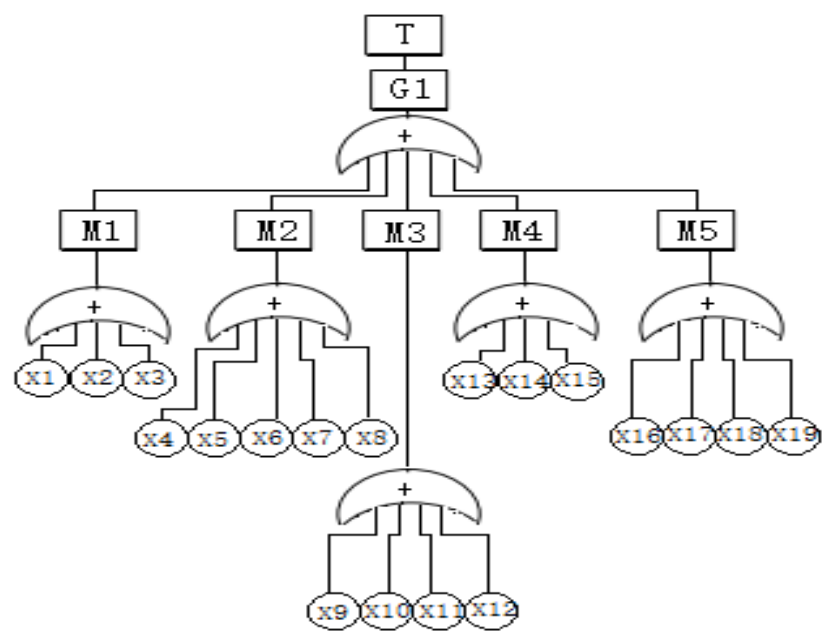

Figure 4. Fault tree of hydraulic support column 
Table 1. Fault tree's event table of hydraulic support column

\begin{tabular}{|c|c|c|c|c|c|}
\hline Grade & Event & Grade & Event & Grade & Event \\
\hline $\mathrm{T}$ & $\begin{array}{c}\text { hydraulic } \\
\text { support fault }\end{array}$ & $\mathrm{X} 3$ & joints with cracks & $\mathrm{X} 12$ & $\begin{array}{c}\text { pipe leakage and } \\
\text { blockage }\end{array}$ \\
\hline G1 & golumn failure & $\mathrm{X} 4$ & globe valve small & $\mathrm{X} 13$ & safety valve failure \\
\hline M1 & emulsion failure & X5 & $\begin{array}{l}\text { pump pressure is not } \\
\text { enough, flow is small }\end{array}$ & $\mathrm{X} 14$ & $\begin{array}{l}\text { hydraulic control check } \\
\text { valve does not work }\end{array}$ \\
\hline M2 & $\begin{array}{l}\text { no rise or slow } \\
\text { speed }\end{array}$ & X6 & column channeling & $\mathrm{X} 15$ & column leakage \\
\hline M3 & $\begin{array}{c}\text { no drop or slow } \\
\text { speed }\end{array}$ & $\mathrm{X} 7$ & system blockage & $\mathrm{X} 16$ & low pump pressure \\
\hline M4 & $\begin{array}{c}\text { drop } \\
\text { spontaneously }\end{array}$ & $\mathrm{X} 8$ & deformation of column & $\mathrm{X} 17$ & operating time is short \\
\hline M5 & $\begin{array}{l}\text { Insufficient } \\
\text { support }\end{array}$ & X9 & $\begin{array}{l}\text { globe valve is not open } \\
\text { enough }\end{array}$ & $\mathrm{X} 18$ & $\begin{array}{c}\text { adjustment safety valve is } \\
\text { low }\end{array}$ \\
\hline $\mathrm{X} 1$ & $\begin{array}{l}\text { seal damage or } \\
\text { size error }\end{array}$ & $\mathrm{X} 10$ & check valve is not open & X19 & relief valve does not work \\
\hline $\mathrm{X} 2$ & groove defect & $\mathrm{X} 11$ & control valve error & & \\
\hline
\end{tabular}

The fault tree of hydraulic support column is analyzed qualitatively, by using Boolean algebra method. The minimum cut set of the fault tree of the hydraulic support column including $\{\mathrm{X} 1\},\{\mathrm{X} 2\},\{\mathrm{X} 3\},\{\mathrm{X} 4\},\{\mathrm{X} 5\},\{\mathrm{X} 6\},\{\mathrm{X} 7\},\{\mathrm{X} 8\},\{\mathrm{X} 9\},\{\mathrm{X} 10\},\{\mathrm{X} 11\}$ $,\{\mathrm{X} 12\},\{\mathrm{X} 13\},\{\mathrm{X} 14\},\{\mathrm{X} 15\},\{\mathrm{X} 16\},\{\mathrm{X} 17\},\{\mathrm{X} 18\}$ and $\{\mathrm{X} 19\}$.

\section{Establishment of Knowledge Base based on Fault Tree}

All diagnostic rules are stored in the system database in accordance with the data table, through the systematic arrangement of industry standards, a priori knowledge and expert experience. The system is designed to realize the knowledge base of the diagnostic system by means of the rule parameter table, the fault tree table and the diagnosis conclusion table $[4,6]$.

Rule parameter table is composed of the inference rules of the storage system and the reasoning of the failure mode with 7 fields [4], as shown in table 2. Rule expressed in RXXX represents the number of the rules. ID expressed in FXX is used to identify the hierarchy and location of the failure mode. Fault storage failure mode of the text, which is the level fault. Fault Father stores the parent node failure mode of the text, which is advanced fault. Logic uses $0 / 1$ to express the logical relation of each other. Confidence level indicates the confidence of the fault including $0,0.3,0.5,0.8,1$. Used represent the number of times and the default is 0 .

Table 2. Rule parameter table

\begin{tabular}{ccccccc}
\hline Rule & ID & Fault & Father Fault & Logic & Confidence level & Used \\
\hline R001 & F01 & golumn failure & $\begin{array}{c}\text { hydraulic } \\
\text { support fault }\end{array}$ & 1 & 0.8 & 0 \\
R002 & F0101 & no rise or slow speed & golumn failure & 1 & 0.5 & 1 \\
R003 & F010101 & $\begin{array}{c}\text { Pump pressure is not } \\
\text { enough, flow is small }\end{array}$ & $\begin{array}{c}\text { no rise or slow } \\
\text { speed }\end{array}$ & 1 & 0.5 & 1 \\
\hline
\end{tabular}

Fault tree table is used to storage fault parameter of basic information as the initial entry of the system fault diagnosis with 5 fields, as shown in table 3. ID represents the identity of the failure mode. Fault represents a failure mode. Logic uses $0 / 1$ to express the logical relation of each other, 0 on behalf of "and", 1 on behalf of "or". Method indicates the failure mode and the technical method of fault detection. Information indicates the level of the fault model and testing standards, etc. 
Table 3. Fault tree table

\begin{tabular}{ccccc}
\hline ID & Fault & Logic & Method & Information \\
\hline F0101 & no rise or slow speed & 1 & $\ldots \ldots$ & $\ldots \ldots$ \\
F010101 & $\begin{array}{l}\text { Pump pressure is not } \\
\text { enough, flow is small }\end{array}$ & 1 & $\ldots \ldots$ & $\ldots \ldots$ \\
\hline
\end{tabular}

Diagnosis conclusion table is used to storage diagnostic conclusion with 3 fields, as shown in table 4. ID represents the identity of the failure mode. Causation describes the specific description of the fault cause. Advice storage of the failure of the maintenance recommendations

Table 4. Diagnosis conclusion table

\begin{tabular}{clc}
\hline ID & \multicolumn{1}{c}{ Causation } & Advice \\
\hline F010101 & $\begin{array}{l}\text { Pump pressure is not } \\
\text { enough, flow is small }\end{array}$ & $\begin{array}{c}\text { eliminate leakage and blockage or replace the line or } \\
\text { Regulate pump station pressure }\end{array}$ \\
\hline
\end{tabular}

\section{Fault Diagnosis Experiment of Hydraulic Support}

The system uses the VisTwo's Marco software to realize the platform development of human-computer interaction interface. The fault diagnosis expert system for fully mechanized mining hydraulic support based on FTA is designed based on the C/S (client and server) network model, which is also combined with Server SQL data and OPC data interface protocol[7]. The login screen of the system is shown in Figure 5

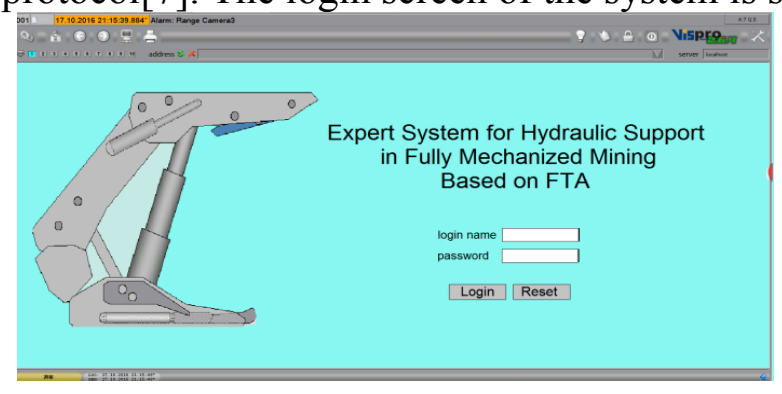

Figure 5 The login screen of the system

Through the establishment of the fault tree of the hydraulic support column, the fault tree nodes are T-G1-M2-X5. The No. 5 hydraulic support is chose for fault diagnosis, after logging into the fault diagnosis of the success of the page. We chose the failure mode "fully mechanized hydraulic support column failure" and the corresponding fault phenomenon "column does not rise or slow speed", then lick the "diagnosis" button to enter the system's fault diagnosis, as shown in Figure 6 (a). According to the interface to select the appropriate options, click on the "2 pump pressure, small flow", select "may", then click next, enter the fault knowledge base and call rules, output diagnosis conclusion and maintenance recommendations, as shown in Figure 6(b). 


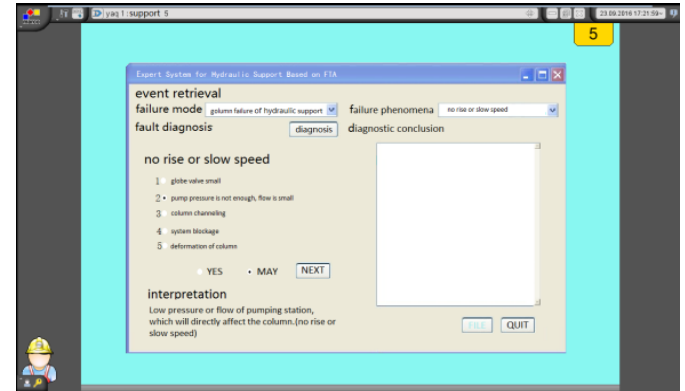

(a) Failure phenomenon

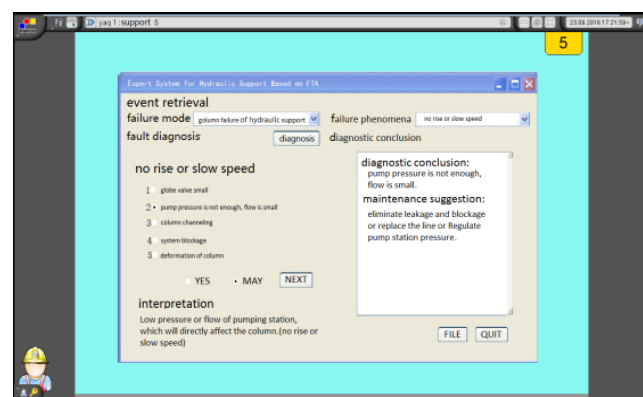

(b) Fault diagnosis conclusion

Figure 6 Interface of fault diagnosis

Comparing the experience of maintenance engineers, the method improves the work efficiency and complete system fault diagnosis through experimental verification. After diagnosis, the appropriate menu and the actual failure of the phenomenon is selected. Through repeated reasoning, the system completes the fault diagnosis by achieving the event rules and the phenomenon of mutual matching. Finally, fault causes, diagnosis and treatment suggestions are displayed on the screen.

\section{Summary}

The fault tree of expert rule based reasoning is applied to fault diagnosis of hydraulic support in coal mine in this paper. The system achieves high efficiency diagnosis of hydraulic support, which is combined with fault tree and expert system. To a certain extent, the system improves the automation and intelligence of the fault diagnosis of fully mechanized mining hydraulic support. Because of convenient operation and high efficiency, the system meets the requirements of high yield and high efficiency coal mine modernization construction.

\section{References}

[1] Guofa Wang. Hydraulic Support Technology [M]. Beijing: Coal Industry Press, 1999.

[2] Shixin Liu. Fault Diagnosis Expert System for Substation Equipment Based on Fault Tree [D]. North China Electric Power University (Beijing), 2007.

[3] Weixing Li. Fault Diagnosis and Analysis of Hydraulic Support Hydraulic System of Fully Mechanized Coal Face[D]. Shandong University of Science and Technology, 2009.

[4] Fulian He, Hongqiang Han. Research on Fault Diagnosis Mechanism and Detection Technology of Hydraulic Support in Fully Mechanized Coal Face[J]. Mining Engineering Research, 2010,01:49-53.

[5] Tete Hu, Yin Liu. Design of Fault Diagnosis Expert System for Hydraulic Support in Coal Mine Based on MATLABGUI[J]. Coal Mining Machinery,2015,12:285-287.

[6] Zheng Chen, Huawang Li. Design of Expert System Reasoning Machine Based on Fault Tree[J]. Computer Engineering, 2012, 11 (38): 228-229.

[7] Bin Weng. Application of Automation System Integration of Fully Mechanized Top Coal Caving Face in Wang Zhuang Coal Mine[J]. Science and Technology Information Development and Economy, 2009,11:196-197. 